\title{
NUMERICAL EVALUATION OF IDLE PARAMETERS OF NOVEL THROTTLE BODY FOR INTERNAL COMBUSTION ENGINES
}

\author{
Karlis Banis \\ Latvia University of Life Sciences and Technologies, Latvia \\ k.banis@yahoo.com
}

\begin{abstract}
The paper investigates and evaluates the idle speed parameters of a novel throttle body for internal combustion gasoline engines. Where the classic throttle bodies utilize a butterfly type valve, a new design has been investigated utilizing a completely different approach in an attempt to eliminate the drawbacks of butterfly type valves. The advantages of the novel design include no obstructions or resistances in the flow-path at fully open throttle position, flow jet centered in the channel cross-section and a slight one-way valve effect at partial throttle openings. Other changes required for the new design include a slightly altered fuel injector angle, a different idle air bypass system and increased leakage at fully closed throttle position. The aim of this study is to evaluate the effects of these design changes on a Honda CRF450R motorcycle at idle speed or fully closed throttle position. Steady state computational fluid dynamics analysis at constant pressure differential was carried out in SolidWorks Flow Simulation environment, where idle speed leakage values were compared between the original butterfly type and the novel design, particle studies were conducted to determine the fuel injection properties. It was found that the novel throttle body is theoretically capable of providing normal idle operation, however, the manufacturing processes should be carefully considered due to the increased leakage at fully closed throttle position. The fuel droplets injected at idle speed tend to travel with greater velocity compared to the original butterfly type throttle body.
\end{abstract}

Keywords: computational fluid dynamics, throttle body, fuel injection.

\section{Introduction}

Throttle body fuel injection systems have been actively used in transport industry for several decades replacing the outdated carburetors. Where the old systems operated by the principle of mechanical fuel delivery driven by the pressure differential across the throttle valve, the new systems comprise an electronic fuel injector, controlled by an electronic metering system. The amount of injected fuel is calculated based on several inputs, such as throttle opening, manifold pressure, engine speed and mass air flow, and controlled by defining the injector open time in each cycle. The use of these inputs allows for a much more precise fuel delivery resulting in greater efficiency, power output and fuel economy.Other advantages include cutting the fuel delivery completely when coasting, as it was discovered that otherwise the intake charge dilutes with exhaust gas [1]. Up to this day, most of the internal combustion gasoline or natural gas engines are designed for stoichiometric air-fuel ratio (AFR) operation necessitating a system for controlling not only the fuel delivery, but also air induction. Typically, this is done by a throttle valve that is reducing the manifold or runner pressure depending on the system layout.Generally, the amount of required fuel in such applications during each cycle is calculated based on the amount of air flowing into the combustion chamber. In road going applications this measurement is carried out by either mass air flow (MAF) sensor or manifold absolute pressure (MAP) sensor. Studies indicate, however, that the correlation between MAP or MAF sensor measurements and throttle opening are sinusoidal rather than linear [2], therefore, performanceoriented applications tend to use a throttle position sensor (TPS) input for a faster reaction time and a more direct link between the user input and air flow.

It was discovered very early that injection must be carried out with high pressure gradient in order to break the fuel down into very fine droplets speeding up the evaporation rate and improving the mixture quality,serving as a basis for high pressure fuel injection development[3].Previous research has also been done on investigating the fuel droplet behavior when confronted by the throttle valve, where it was found that larger droplets will tend to deposit on the valve surface while smaller droplets will follow the air stream around it [4]further necessitating high pressure injections. Since then, several layouts have been tried known as manifold injection, port injection and direct injection. The most common layout is currently port injection, although direct injection is slowly becoming the next industry standard. Research indicates that innon-direct injection systems only $15-20 \%$ of the injected fuel is vaporized between the injector and cylinder [5]. The injector angle and spray pattern are therefore carefully considered for minimizing the wetting of channel walls [6], although eventually unavoidable. For this particular aspect it is the air velocity in the induction system that has a 
significant effect on the transport and vaporization of the fuel deposits [7]. In this regard, careful consideration is also done on the throttle body design itself, as some studies have indicated that the importance of the said design surpasses the importance of the injection or spray pattern [8].

This study is investigating a layout where the throttle valve is placed directly in the intake runner and the injector location is configured in port injection layout as found on a performance-oriented motorcycle Honda CRF450R (see Figure 1). It is known that electronic fuel injection systems needs to accommodate different airflow requirements for idling conditions at temperatures outside of normal operation, such as cold start, to provide for easy starting, avoid stalling the engine when cold and ensure acceptable emissions [9]. Normally, an electronically controlled air bypass system is integrated into the throttle body. On the mentioned motorcycle this system comprises a manual air choke and bypass screw integrated in the idle speed adjusting circuit. The electronic control system utilizes pulsed injection opening the injector once per every intake cycle. Previous studies show that for the idle condition a pulsed fuel injection is not favorable over a steady spray with regard to the size of fuel droplets [10] denoting that a good overall airflow velocity should be maintained in the regions where fuel droplets tend to deposit.

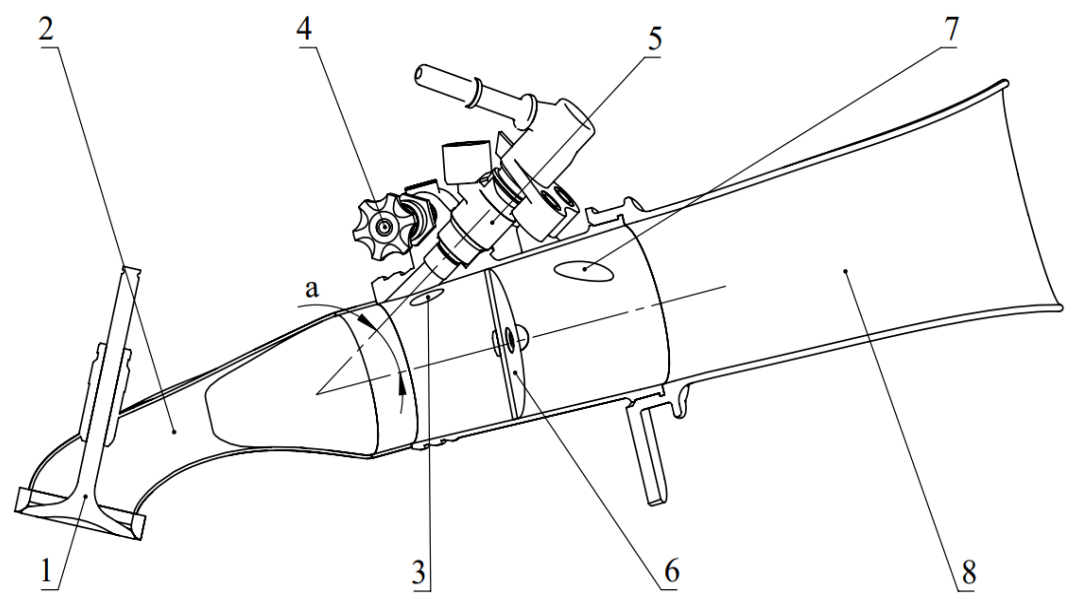

Fig. 1. Honda CRF450R intake system: 1 - intake valve; 2 - intake port; 3 - air bypass outlet; 4 -idle speed adjuster screw; 5 - fuel injector; a - injector angle $\left(30^{\circ}\right) ; 6$ - throttle valve; 7 - air bypass inlet; 8 - intake runner

A novel throttle body [11] has been developed (see Figure 2) to address some of the issues associated with butterfly type throttle valves in partially open and fully open throttle positions. The valve has been designed to be used on Honda CRF450R motorcycle, where some design challenges have led to an altered idle air bypass system and different injector angle. It is therefore the aim of this study to evaluate the effects of these design changes at idle speed or fully closed throttle position.

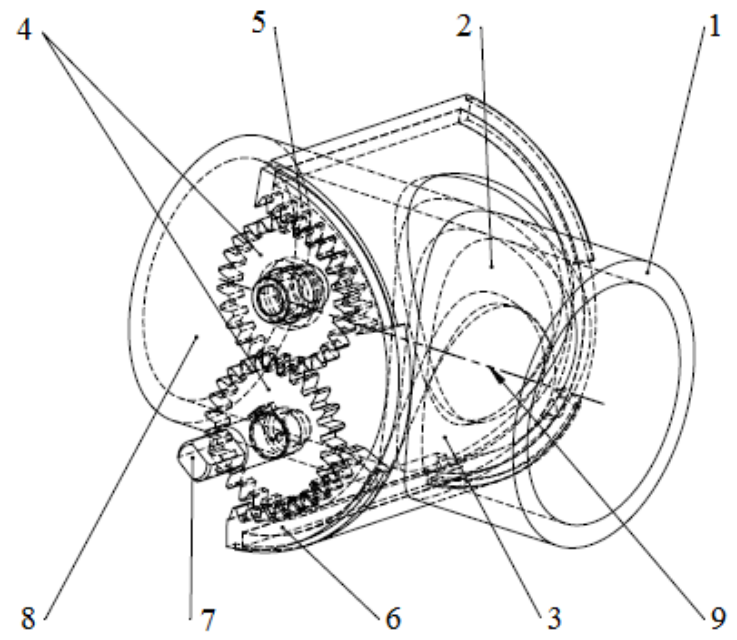

Fig. 2. Throttle valve for internal combustion engines [11]: 1 - body; 2, 3 - valves; 4 - drive gears; 5,6 - internal gear sectors; 7 - driving shaft; 8 - flow channel; 9 - flow axis 


\section{Materials and methods}

The object of investigation is a novelthrottle body [11] at fully closed throttle position or idle speed (see Figure 3). The design of this throttle body itself is prone to certain amount of leakage at fully closed position due to design specifics. It is therefore important to find out if the leakage is severe enough to result in excessive idle speed. It is also important to study the effect of idle speed air flow characteristics and its interaction with the injected fuel to compare the results with the original system. For this purpose, accurate 3D models are created based on the original and novel systems on the basis of which a steady state fluid dynamics study is set up in Solidworks Flow Simulation environment. In order to define the boundary conditions for the study, it is necessary to determine the vacuum created by the engine at idle speed.

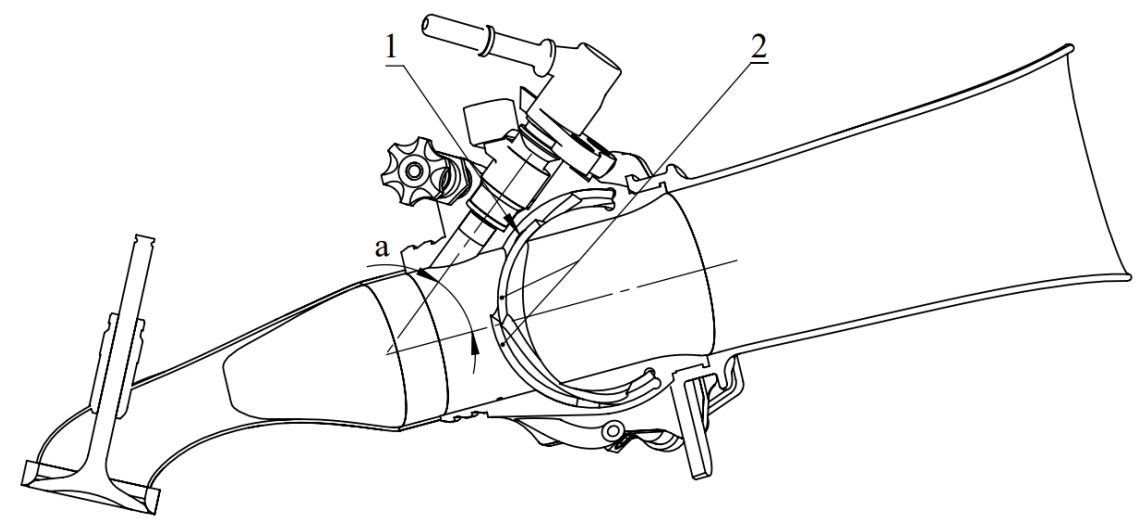

Fig. 3. Intake system comprising the novel throttle body [11]: 1 - air bypass outlet; 2 - throttle valves; a - injector angle $\left(39^{\circ}\right)$

The motorcycle used in this study has been equipped with a fully programmable engine control unit (ECU) Performance Electronics PE3-SP0. This unit allows the user to run trigger diagnostics and save the trigger (variable reluctance) and sync (manifold absolute pressure) sensor readouts as data points. The engine is using a twelve-tooth trigger wheel with one tooth missing. The layout of the trigger wheel in combination with the variable reluctance sensor is illustrated in Figure 4.

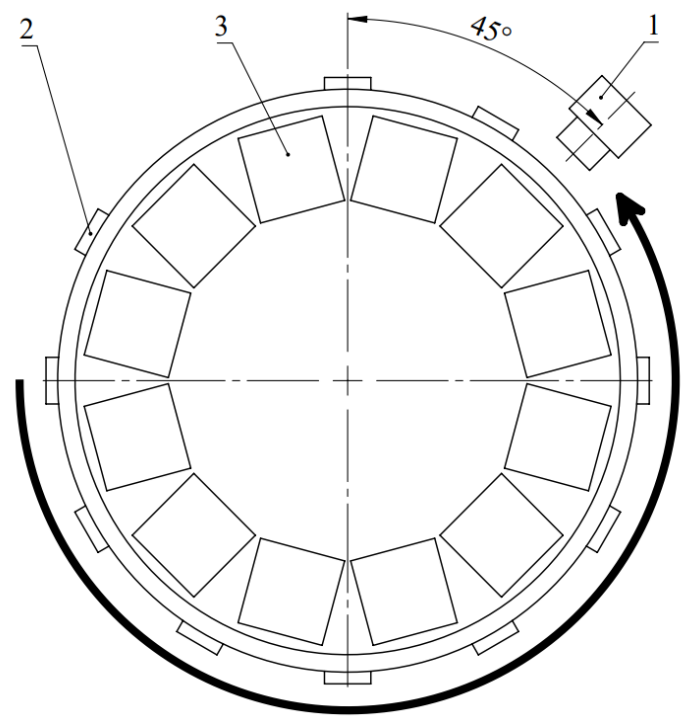

Fig. 4. Honda CRF450R trigger system at top dead center:

1 - variable reluctance sensor; 2 - trigger tooth; 3 - stator winding

To begin the experiment, the engine is started and warmed up to operating temperature $\left(80^{\circ} \mathrm{C}\right)$, while the ECU is in communication mode with a laptop via ethernet cable. The trigger diagnostics is then performed and the resulting data exported to a comma separated file that can be opened by Microsoft Excel. The trigger and sync data as exported are shown in Figure 5. 


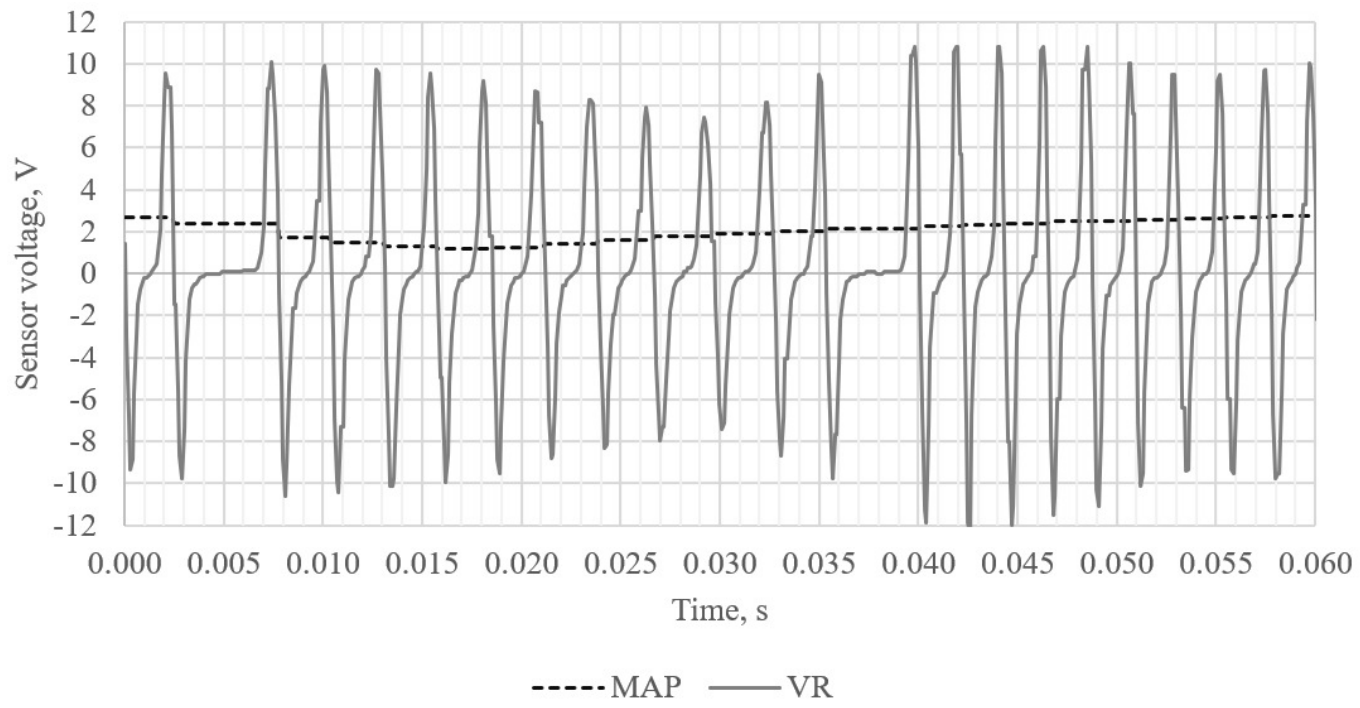

Fig. 5. Manifold absolute pressure (MAP) and variable reluctance (VR) sensor readouts at idle speed

It is visible that sync (MAP) sensor readings range from $1.19 \mathrm{~V}$ to $2.66 \mathrm{~V}$. According to the sensor definitions in Performance Electronics ECU there is a linear relationship between the sensor voltage and the pressure it is exposed to where $0.5 \mathrm{~V}$ corresponds to $73.43 \mathrm{kPa}$ and $4.5 \mathrm{~V}$ corresponds to 119.49 $\mathrm{kPa}$. By using the linear interpolation method given in formula (1) it is then possible to conclude that the manifold absolute pressure during the trigger diagnostics has ranged from $81.38 \mathrm{kPa}$ to $98.30 \mathrm{kPa}$.

$$
y=\frac{y_{0}\left(x_{1}-x\right)+y_{1}\left(x-x_{0}\right)}{x_{1}-x_{0}},
$$

where $y$-resulting pressure at given voltage, $\mathrm{kPa}$;

$y_{0}$ - pressure at $0.5 \mathrm{~V}(73.43 \mathrm{kPa})$;

$y_{1}$ - pressure at $4.5 \mathrm{~V}(119.49 \mathrm{kPa})$;

$x$ - given voltage, $\mathrm{V}$;

$x_{0}-$ lowest voltage point $(0.5 \mathrm{~V})$;

$x_{1}$ - highest voltage point $(4.5 \mathrm{~V})$.

For simplicity purposes, the steady state fluid dynamics analysis will be carried out at manifold pressure corresponding to the moment of fuel injection as the simulation data can later be used to analyze fuel injection behavior. It is visible in Figure 4 that the variable reluctance sensor is placed $45^{\circ}$ away from top dead center (TDC), meaning that in sensor signal TDC is identified as the second air gap from the missing tooth. Furthermore, the fuel injection at idle speed is set to take place 180 degrees of crankshaft rotation after TDC. Based on the twelve teeth layout of the trigger wheel this means that the fuel injection is taking place as the variable reluctance sensor reaches the eighth air gap from the missing tooth. At this crankshaft position the MAP sensor readout is $2.03 \mathrm{~V}$ where according to formula (1) it corresponds to $91.05 \mathrm{kPa}$ pressure. This value is used to define the vacuum boundary condition for the computational fluid dynamics study. The meshing method used for simulation is tetrahedral, resulting in 414,267 cells for the novel throttle body (see Figure 6) and 13,088 cells for the butterfly type throttle body. These figures are vastly different due to the number of small gaps contained in the novel throttle body where fine mesh is required. For the original equipment $(\mathrm{OE})$ system, the air inlet is defined at the main induction channel, but for the novel system, due to the auxiliary air intake port for idle speed circuit, there is an additional air inlet located at this port. The outlet boundaries are defined at the entrance to the combustion chamber on both systems.

The butterfly type throttle body is by design considered gas-tight implying near-zero leakage at fully closed position due to the simple construction. Since the experiments of this study are purely numerical, manufacturing inconsistencies and tolerances are not considered, therefore the leakage rate of original butterfly type throttle body is assumed zero in fully closed valve and bypass screw positions. The novel type throttle body, however, can not satisfy the gas-tight condition consisting of 
several moving part pairs at distances ranging from 0.1 to $0.5 \mathrm{~mm}$, implying an inherent leakage at fully closed position.

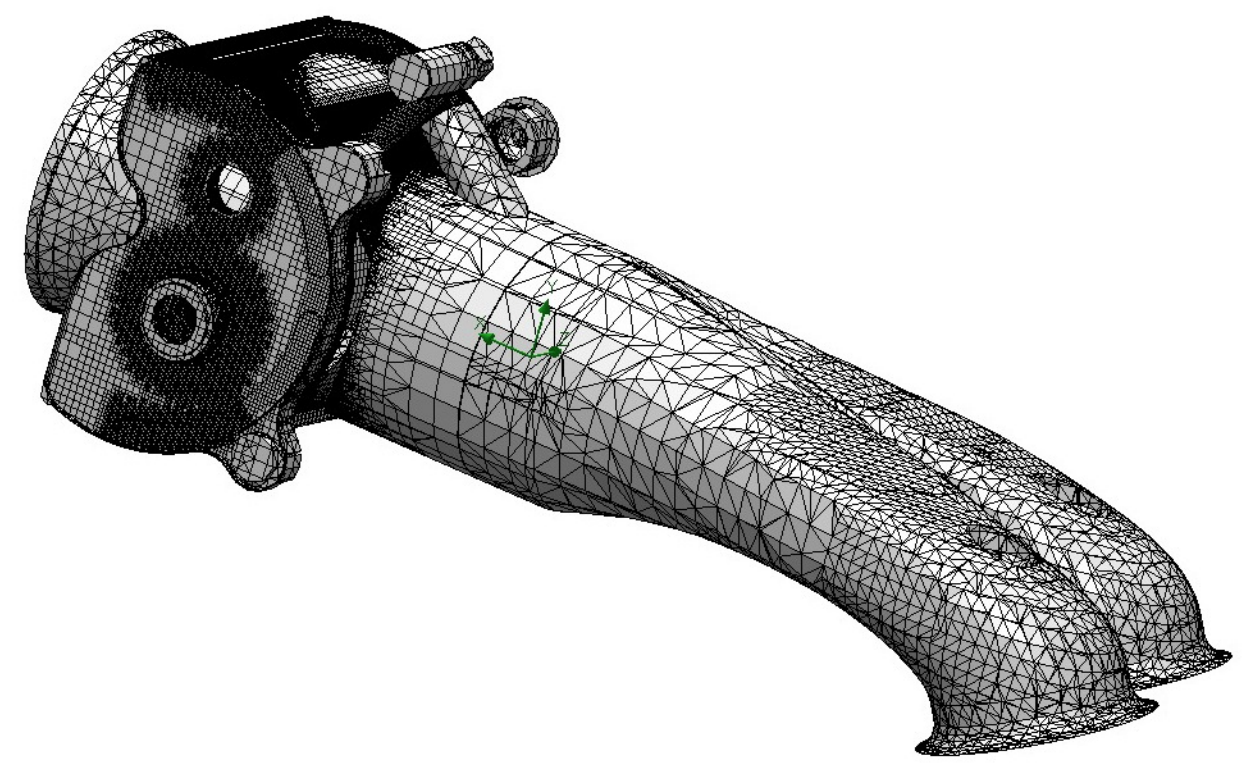

Fig. 6. Simulation mesh of novel throttle body

During further comparison, for the original butterfly type throttle body the idle speed adjuster screw is positioned in default setting, but for the novel throttle body, after running multiple steady state flow simulations and comparing the total mass flow to the original system, the idle speed adjuster screw is then positioned accordingly until equal mass flow rates are achieved between both types of throttle bodies. The results of this test are given in Table 1.

The second study is focused on fuel injection. According to the ECU settings, the target air to fuel ratio at idle speed is 13 parts to one and the mass air flow $1.925 \mathrm{~kg} \cdot \mathrm{h}^{-1}$ which corresponds to 0.148 $\mathrm{kg} \cdot \mathrm{h}^{-1}$ of required fuel flow. The injector open time during the trigger diagnostics at idle speed is shown as $2.21 \mathrm{~ms}$. The time necessary for the complete engine cycle at idle speed can be calculated according to formula (2).

$$
t=\frac{n \cdot 60}{N} \cdot 10^{3},
$$

where $t$ - time required for a complete engine cycle, ms;

$n$ - number of crankshaft revolutions per cycle;

$N$ - engine speed, $\min ^{-1}$.

The total amount of air ingested during this time can then be found applying formula (3).

$$
m=t \cdot \frac{Q_{a}}{3.6 \cdot 10^{6}},
$$

where $m$-total mass of ingested air, $\mathrm{kg}$;

$t$ - time required for a complete engine cycle, ms;

$Q_{a}$ - mass air flow, $\mathrm{kg} \cdot \mathrm{h}^{-1}$.

It is important to understand that Solidworks flow simulation particle study requires the definition of mass fuel flow from the injector nozzle. Thus, the mass, as injected over the period of $2.21 \mathrm{~ms}$ injector pulse width it has to conform with air fuel ratio of 13 parts to 1 . The necessary fuel flow can be obtained by applying formula (4).

$$
Q_{f}=\frac{m}{A F R \cdot p} \cdot 3.6 \cdot 10^{6},
$$


where $Q_{f}$-mass fuel flow, $\mathrm{kg} \cdot \mathrm{h}^{-1}$;

$m$ - total mass of ingested air, $\mathrm{kg}$;

$A F R$ - air fuel ratio;

$p$-injector pulse width, ms.

The end result is a mass fuel flow of $4.02 \mathrm{~kg} \cdot \mathrm{h}^{-1}$. Solidworks particle study also allows the definition of the particle size and initial velocity. According to the findings of [12], the mean droplet size for common gasoline injectors is $9 \cdot 10^{-5} \mathrm{~m}$ at velocity of $\sim 10 \mathrm{~m} \cdot \mathrm{s}^{-1}$. The fluid used for the particle study is RON98 gasoline and the injection is defined in 10 different points located at the face of the injector tip.

\section{Results and discussion}

The steady state flow simulation results (Table 1) show that in order for the novel throttle body design to reach mass air flow comparable to that of OE system, the air bypass screw should be at a position corresponding to 0.4 turns less than original. According to the design limits of the air bypass screw, this is fully achievable and should impose no complications providing the right amount of mass air flow for idle speed at $2000 \mathrm{~min}^{-1}$ which is the nominal for the motorcycle in question.

Table 1

Mass flow rates at idle speed

\begin{tabular}{|c|c|c|}
\hline Air bypass screw position & OE throttle body, $\mathbf{~ k g} \cdot \mathbf{h}^{\mathbf{- 1}}$ & Novel throttle body, $\mathbf{~ k g} \cdot \mathbf{h}^{\mathbf{- 1}}$ \\
\hline 0.0 turns & 0.000 & 0.720 \\
\hline 1.3 turns & 1.076 & 1.925 \\
\hline 1.7 turns & 1.925 & 2.650 \\
\hline
\end{tabular}

The particle injection study is run separately after the mass air flow calculations are finished. Solidworks is able to export each injection point as a trajectory, tracking the particles as they travel downstream. The starting points of each trajectory have been selected evenly spaced from the injector end face. The results show a noticeable increase in average particle velocity for the experimental type throttle body (Table 2, Fig. 7). This could be explained by the additional leakage of the experimental throttle valve at fully closed position introducing more individual streams of air from multiple directions rather than a single stream from the air bypass circuit as found on the original butterfly type throttle body. The average particle velocity across all trajectories was increased by $16.91 \%$, indicating a possibleimprovement in mixture quality over the original system at idle speed.

Table 2

Average gasoline particle velocities

\begin{tabular}{|c|c|c|}
\hline Trajectory & Original throttle body, $\mathbf{~ m} \cdot \mathbf{s}^{-\mathbf{1}}$ & Novel throttle body, $\mathbf{~ m} \cdot \mathbf{s}^{\mathbf{- 1}}$ \\
\hline 1 & 3.71 & 3.92 \\
\hline 2 & 3.26 & 3.68 \\
\hline 3 & 3.19 & 4.03 \\
\hline 4 & 3.25 & 4.17 \\
\hline 5 & 3.21 & 3.99 \\
\hline 6 & 3.28 & 4.04 \\
\hline 7 & 3.51 & 3.87 \\
\hline 8 & 3.66 & 4.05 \\
\hline 9 & 3.47 & 4.13 \\
\hline 10 & 3.68 & 4.25 \\
\hline Average & 3.43 & 4.01 \\
\hline
\end{tabular}

The theoretical results of the study suggest that the novel throttle body according to [11] as designed for use on a Honda CRF450R motorcycle is capable of providing the correct amount of mass air flow to prevent the engine from exceeding idle speed of 2,000 $\mathrm{min}^{-1}$ and the altered idle speed air streams provide for an improved mixture quality at fully closed valve position resulting in normal idle operation. Where typically a steeper injector angle would degrade the air-fuel mixing process and 
promote wetting of the channel walls, this does not seem to be the case with the novel throttle body possibly due to the number of individual air streams introduced in the system from the leakage.

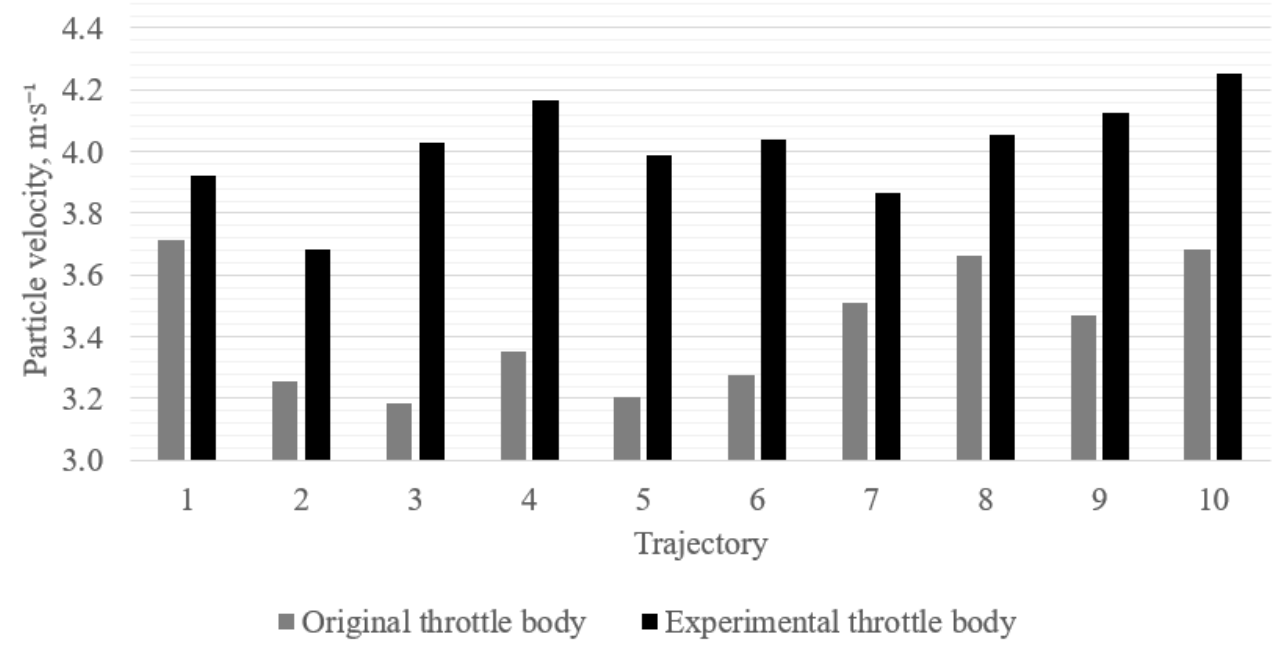

Fig. 7. Average gasoline particle velocities

\section{Conclusions}

1. Two CAD models of throttle bodies for Honda CRF450R motorcycle were created: the original butterfly type and novel throttle body [11].

2. Trigger diagnostics was run on the said motorcycle and intake vacuum determined in relation to angular position of the crankshaft to be used for computational fluid dynamics (CFD) study.

3. Static leakage rate of the experimental throttle body type was evaluated and compared to the original throttle body using CFD. The experimental throttle body requires additional 0.4 turns of the air bypass screw to reach the mass air flow equivalent to the original system with no leakage.

4. Gasoline particle injection was run in the CFD environment at 10 different injection points. The average gasoline particle velocity of the experimental type throttle body was found to be $16.91 \%$ higher than the original system, indicating a possible improved mixture quality at idle speed.

5. In order to properly evaluate the differences and compare the designs, the experimental type throttle body should be manufactured and tested on the same motorcycle in real conditions.

\section{Acknowledgements}

This publication has been prepared within the framework of the Latvia University of Life Sciences and Technologies project "Z25 - Innovative improvements of gas exchange system efficiency for internal combustion engines" of programme "Strengthening of scientific capacity 2018".

\section{References}

[1] Mock F., Suttle W., Problems of fuel injection for gasoline automobile engines. SAE Technical Paper No. 550217, 1955.

[2] Chang S., Yaacob Z., Mohsin R. Effect of various manifold absolute pressures and air flowrates on throttle body injection mixer in compressed natural gas motorcycle. Journal of Chemical and Natural Resources Engineering, vol. 1, 2007, pp. 40-49.

[3] Zhao F. Q., Lai M. C., Harrington D. L. The spray characteristics of automotive port fuel injection - a critical review. SAE Technical Paper No. 950506, 1995.

[4] Nogi T., Ohyama Y., Yamauchi T.,Kuroiwa H. Mixture formation of fuel injection systems in gasoline engines. SAE Technical Paper No. 880558, 1988.

[5] Boam D. J., Finlay I. C., Fairhead G. S. The Optimization of fuel enrichment patterns with throttle body injection. Proceedings of the institution of mechanical engineers, Part D: Transport engineering, January 1, 1988, vol. 202(1), pp. 9-20.

[6] Gyorki J., Fundamentals of electronic fuel injection. SAE Technical Paper No. 740020, 1974. 
[7] Nagaishi H., Miwa H., Kawamura Y., Saitoh M. (1989). An analysis of wall flow and behavior of fuel in induction systems of gasoline engines. SAE Technical Paper No. 890837, 1989.

[8] Coverdill R. E., Kirwan J. E., Brandon I. E., Peters J. E. The effects of throttle body injection on fuel/air distribution in a spark ignition engine. "Combustion Science and Technology", vol. 66(46), 1989, pp. 189-198.

[9] Shankar R., Udayakumar G., Sasikumar K., Advanced port injection solution for motorcycle application. SAE Technical Paper 2008-28-0031, 2008.

[10] Kirwan J.E., Dralimeier J.A., Coverdill R.E., Crawford R.R., PetersJ.E. Spray characteristics of throttle body fuel injection. SAE Transactions, January 1, 1989, vol. 98, pp. 415-424.

[11] Throttle valve for internal combustion engines. Patent No. LV15411. [online][30.04.2020]. Available at: https://worldwide.espacenet.com/patent/search/family/061622652/publication/LV15411A?q = pn $\% 3 \mathrm{DLV} 15411 \mathrm{~A}$

[12] Jiang C. Parker M.C., Spencer A., Wigley G., Garner C.P., Helie J. Droplet size development in a DISI injector fuel spray. Proceedings of the 18th international symposium on application of laser and imaging techniques to fluid mechanics, Lisbon, Portugal, July 4-7, 2016, pp. 2834-2847. 